\title{
Anaplasmose transplacentária em bovino no Rio Grande do Sul: relato de caso
}

Gilson Antonio Pessoa, Leandro do Monte Ribas, William Oliveira Vasques, Wellison Santos de Souza, Claiton Henrique Salib Velho, Letícia Dossin Regianini

Universidade de Caxias do Sul (UCS), Caxias do Sul, RS, Brasil

*Autor correspondente

e-mail: gilsonpessoavet@yahoo.com.br

\section{Resumo}

A anaplasmose bovina, doença que acomete os ruminantes, é causada pelo Anaplasma spp., parasita intraeritrocitário pertencente à ordem Rickettsiales, que também pode ser encontrado livre no plasma. Em conjunto com a Babesia spp. forma o complexo denominado Tristeza Parasitária Bovina. A transmissão de $A$. marginale pode ocorrer mecanicamente por dípteros hematófagos, fômites contaminados e, biologicamente, através do carrapato microplus, considerado o principal vetor no Brasil, e também por via transplacentária, cuja forma é menos comum. Tendo em vista a baixa ocorrência em bezerros neonatos, este trabalho descreve a ocorrência de anaplasmose transplacentária em um bovino macho da raça Hereford, com três dias de vida, originário do município de Ipê/RS, atendido em setembro de 2016 no ambulatório veterinário de grandes animais da Universidade de Caxias do Sul, Rio Grande do Sul. 0 animal apresentava-se apático, em decúbito lateral, sem conseguir manter-se em estação, hipertermia (40,2 ํㅡ), taquipnéia, mucosas ictéricas e desidratação grave (> 10\%), onde foi estipulado o tratamento adequado para o caso de infecção por Anaplasma spp. No hemograma foi observada anemia acentuada com anisocitose e policromasia, hipoproteinemia, e plasma ictérico. No leucograma, constatou-se leucocitose com desvio à esquerda e linfocitose. 0 animal veio a óbito entre o terceiro e quarto dia de internação, sendo então encaminhado para o setor de patologia veterinária da Universidade de Caxias do Sul. À necropsia, observou-se icterícia generalizada; linfonodo axilar direito e mesentéricos moderadamente aumentados; ascite discreta; fígado com coloração alaranjada; baço aumentado e, ao corte, apresentando-se de aspecto pulposo; intestino seroso amarelado e com alguns segmentos com petéquias; rins amarelados; cavidade torácica com hidrotórax discreto e pulmões não colapsados, hemorragia na superfície pleural e edema na superfície de corte; traqueia com edema no lúmen; e coração com o epicárdio com áreas de hemorragia e hematócitos em válvula mitral. No exame histológico, o fígado apresentou colestase acentuada, o linfonodo axilar demonstrou presença 
de infiltrado histiocitário multifocal, baço com congestão e hiperplasia linfoide moderadas, e cérebro com congestão difusa moderada. Os achados patológicos apresentados caracterizaram uma anemia hemolítica extravascular causada pelo hemoparasita Anaplasma marginale. Os exames complementares e sinais clínicos sugeriram o diagnóstico de infecção por via transplacentária do bezerro em função da idade e do período de incubação deste parasita. A transmissão tem sido relacionada à ocorrência da forma aguda na matriz durante a prenhez, principalmente no terço final de gestação. Apesar de existirem poucos relatos de infecção transplacentária e de o tratamento ser pouco efetivo com os neonatos, mesmo quando submetidos à terapia intensiva, o manejo profilático do rebanho se torna um método de controle muito importante para a redução dos casos de anaplasmose, evitando perdas econômicas na criação. 